\title{
ALTAS CONCENTRAÇÕES DE FSH-p NA MATURAÇÃO In vitro DE OÓCITOS Bos indicus ${ }^{1}$
}

\author{
HIGH CONCENTRATIONS OF FSH-p ON THE In vitro MATURATION \\ OF Bos indicus OOCYTES
}

\author{
Joana D'Arc Rocha Alves ${ }^{2}$ Marcos Antonio Lemos Oliveira ${ }^{3}$ Paulo Fernandes Lima ${ }^{3}$ \\ João Gustavo Luz Caldas ${ }^{4}$ Antônio Santana Santos Filho ${ }^{4}$ \\ Marcia Brayner Paes Barreto ${ }^{3}$
}

RESUMO

O objetivo deste trabalho foi avaliar a eficiência de diferentes concentrações de um FSH-p comercial sobre a maturação nuclear de oócitos Bos indicus, clivagem $e$ desenvolvimento in vitro de embriões até estádios de blastocisto. Após seleção e transferência para o meio TCM 199/HEPES suplementado com diferentes concentrações de FSH-p $(T 1=$ $10 \mu \mathrm{g} / \mathrm{m} \ell ; T 2=20 \mu \mathrm{g} / \mathrm{m} \ell ; T 3=40 \mu \mathrm{g} / \mathrm{m} \ell$ ), os oócitos foram incubados, durante 24 horas, a $39^{\circ} \mathrm{C}$ em atmosfera úmida contendo $5 \%$ de $\mathrm{CO}_{2}$. Parte dos oócitos foram retirados para análise da maturação nuclear e os demais foram transferidos para o meio de fecundação (mDM). Após 18 horas de incubação nas mesmas condições atmosféricas mencionadas para os oócitos, os presumíveis zigotos foram distribuídos no meio de desenvolvimento embrionário (KSOM) contendo monocamada de células da granulosa. As porcentagens de metáfase II, de clivagem e de blastocisto foram, respectivamente, de 81,8/62,5/17,6\% (T1); 55,6/64,0/19,5\% (T2) e 50,0/65,0/16,3\% (T3). A análise estatística revelou que uma menor porcentagem $(P \leq 0,05)$ de oócitos tratados com $20 \mu \mathrm{g} / \mathrm{m} \ell$ e $40 \mu \mathrm{g} / \mathrm{m} \ell$ de FSH-p alcançou o estádio de metáfase II e que as taxas de clivagem $e$ blastocisto não diferiram $(P \geq 0,05)$ entre os tratamentos. Os resultados permitem concluir que a adição de $20 \mu \mathrm{g} / \mathrm{m} \ell e$ $40 \mu \mathrm{g} / \mathrm{m \ell}$ de FSH-p ao meio de cultura interfere no processo de maturação nuclear, mas todas as concentrações testadas podem ser utilizadas sem prejuízo aparente para a clivagem $e o$ posterior desenvolvimento embrionário.

Palavras-chave: maturação, clivagem, blastocisto, FSH-p.

\section{SUMMARY}

The aim of this work was to evaluate the efficiency of different concentrations of a commercial FSH-p on the nuclear maturation of Bos indicus oocytes, cleavage and in vitro development of embryos until blastocyst stages. The oocytes were selected and transferred to the maturation medium (TCM 199/25 mM HEPES) supplemented with different concentrations of FSH$p(T 1=10 \mu \mathrm{g} / \mathrm{m} \ell ; T 2-20 \mu \mathrm{g} / \mathrm{m} \ell ; T 3-40 \mu \mathrm{g} / \mathrm{m} \ell)$ and after 24 hours of incubation, at $39^{\circ} \mathrm{C}$ in a moist $5 \% \mathrm{CO}_{2}$ atmosphere. Some of the oocytes were removed and submitted to the analysis of nuclear maturation and the others were placed in the fertilization medium (mDM). After 18 hours of incubation, at the same atmosfhere condition mentioned above, the presumptive zygotes were transferred to the culture medium (KSOM) with a granulosa cells monolayer. The metaphase II, cleavage and blastocyst percentages were, respectively, 81.8/62.0/17.6\% (T1), $55.6 / 64.0 / 19.5 \%(T 2)$ and $50.0 / 65.0 / 16.3 \%$ (T3). The statistic analysis showed that a lower percentage of oocyte $(P \leq 0.05)$ treated with $20 \mu \mathrm{g} / \mathrm{m} \ell$ and $40 \mu \mathrm{g} / \mathrm{m} \ell$ of $F S H-p$ reached the metaphase II stage and that the cleavage and blastocyst rate do not differ among treatments $(P \geq 0.05)$. The results allow to conclude that the addition of $20 \mu \mathrm{g} / \mathrm{m} \ell$ and $40 \mu \mathrm{g} / \mathrm{m} \ell$ of FSH-p to the culture medium interfere in the nuclear maturation process, however all tested concentrations may be used without apparent damage to the cleavage and subsequent embryonic development.

Key words: maturation, cleavage, blastocyst, FSH-p.

\section{INTRODUÇÃO}

A produção in vitro de embriões tem-se constituído em eficiente instrumento de auxílio para a produção de animais zootecnicamente explorados, no entanto, essa biotécnica não mantém uma regularidade de resultados. Por isso, uma série de

\footnotetext{
${ }^{1}$ Parte da Dissertação do primeiro autor apresentada à Universidade Federal Rural de Pernambuco (UFRPE) para obtenção do grau de Mestre em Ciência Veterinária.

${ }^{2}$ Médico Veterinário, MSc, Departamento de Medicina Veterinária, UFRPE, Av. D. Manoel de Medeiros, S/N, Dois Irmãos, 52171-900,

Recife, PE. E-mail:.maloufrpe@uol.com.br. Autor para Correspondência.

${ }^{3}$ Professor, Departamento de Medicina Veterinária, UFRPE.

${ }^{4}$ Discente do Programa de Pós-graduação em Ciência Veterinária, UFRPE. 
fatores precisam ser melhor esclarecidos para contribuir com a difusão desta tecnologia e, dentre eles, a maturação de oócitos continua sendo assunto de relevância pela necessidade dos eventos citoplasmático, nuclear e de membrana ocorrerem sincronicamente (YANG et al., 1998) para não haver prejuízo da fecundação e do posterior desenvolvimento embrionário (SUSS et al., 1988).

Apesar da divergência entre os mais variados protocolos de maturação in vitro de oócitos bovinos, existe a unanimidade de ser necessário suplementar o meio de maturação com LH (BRACKETT et al., 1989; YOUNIS et al., 1989), FSH (SCHNEIDER, 1997; ALVES et al., 1999) ou ainda através da suplementação com ambas gonadotropinas (SAEKI $\boldsymbol{e t}$ al., 1991; SIMPLÍCIO et al.,1997). Além disso, a associação entre hormônios gonadotróficos e esteróides (MONTAGNER, 1999) também tem sido implementada em função da especificidade de ação que cada hormônio deve exercer tanto para maximizar a porcentagem de oócitos que completam a meiose quanto para aumentar a capacidade de fecundação e de desenvolvimento até estádios de blastocisto (FUKUSHIMA \& FUKUI, 1985; FUKUI, 1989; FUKUI \& ONO, 1989; SAEKI et al., 1991).

É sabido que a suplementação do meio de maturação de oócitos com FSH induz um aumento transitório do AMPc (RICHARD, 1980) que pode retardar a retomada do processo de meiose, razão pela qual vários grupos de pesquisa têm utilizado alta concentração de LH e baixa de FSH (BRACKETT et al., 1989; MONTAGNER, 1999; ZUELKE \& BRACKETT, 1990). Por outro lado, a literatura tem mostrado a possibilidade de ser utilizado até $10 \mu \mathrm{g} / \mathrm{m} \ell$ de FSH no meio de maturação sem aparente prejuízo para os processos de clivagem e de desenvolvimento de estruturas embrionárias até estádios passíveis de transferência para receptoras (SCHNEIDER, 1997; ALVES, et al., 1999).

Partindo-se do princípio de que amostras de FSH-p comercial são contaminadas com LH e do fato de não ter sido ainda testada concentração maior do que $10 \mu \mathrm{g} / \mathrm{m} \ell$ de FSH-p na maturação in vitro de oócitos Bos indicus, conduziu-se esse trabalho para verificar a influência das concentrações de $20 \mu \mathrm{g} / \mathrm{m} \ell$ e $40 \mu \mathrm{g} / \mathrm{m} \ell$ de FSH-p contendo $20 \%$ de LH sobre a produção in vitro de embriões, haja vista a influência do LH sobre os eventos responsáveis pela maturação.

\section{MATERIAL E MÉTODOS}

Os ovários da espécie Bos indicus foram obtidos em abatedouro na Região Metropolitana do Recife-PE. Em um período máximo de uma hora, os ovários eram transportados ao laboratório em garrafa térmica contendo solução fisiológica acrescida de $30 \mu \mathrm{g} / \mathrm{m} \ell$ de sulfato de gentamicina em temperatura variando de 30 a $35^{\circ} \mathrm{C}$.

Em 10 repetições, foi utilizado um total de 750 oócitos obtidos de folículos medindo de 2 a $5 \mathrm{~mm}$ de diâmetro, os quais foram aspirados com auxílio de seringa de $5 \mathrm{~m} \ell$ e agulha $18 \mathrm{~g}$. O líquido folicular foi depositado em cálice que continha o meio de lavagem constituído por $8,0 \mathrm{mg}$ de bicarbonato de sódio, 45,0mg de glucose, $5,6 \mathrm{mg}$ de piruvato de sódio, 11,9mg de Hepes, 2,5mg de sulfato de gentamicina e 20,0mg de álcool polivinílico em 50m $\ell$ de TALP. Para sedimentação e obtenção do complexo cumulus/oócito, o líquido folicular permaneceu em repouso durante 15 minutos a $39^{\circ} \mathrm{C}$. Após desprezar-se o sobrenadante, o complexo cumulus/oócito foi depositado em placa de Petri para recuperação e seleção dos oócitos. Uma vez selecionados, com base na aparência morfológica descrita por YOUNIS et al. (1989), os oócitos foram lavados (5 vezes) no meio anteriormente mencionado para, em seguida, serem colocados, 25 oócitos em gotas de $100 \mu \ell$ sob óleo de parafina, no meio de maturação (TCM $19925 \mathrm{mM}$ Hepes $^{\text {a }}$ ) formulado de acordo com KESKINTEPE \& BRACKETT (1996). Esse meio foi suplementado com diferentes concentrações de uma única partida de FSH-p ${ }^{\mathrm{b}}$ contendo $20 \%$ de LH $(10 \mu \mathrm{g} / \mathrm{m} \ell, 20 \mu \mathrm{g} / \mathrm{m} \ell$ e $40 \mu \mathrm{g} / \mathrm{m} \ell$ ). Imediatamente após, os oócitos foram incubados a $39^{\circ} \mathrm{C}$ em atmosfera úmida contendo $5 \%$ de $\mathrm{CO}_{2}$ durante 24 horas.

Após o descongelamento à $37^{\circ} \mathrm{C}$ por 10 segundos, as palhetas que continham sêmen de $\boldsymbol{B o s}$ taurus $\left(1 \times 10^{7}\right.$ espermatozóides em $\left.0,5 \mathrm{~m} \ell\right)$ foram desinfectadas com álcool $70^{\circ}$ e levadas para um ambiente climatizado à $39^{\circ} \mathrm{C}$. Cuidadosamente, $0,1 \mathrm{~m} \ell$ de sêmen foi depositado em tubos cônicos de centrífuga contendo $1,5 \mathrm{~m} \ell$ de meio definido modificado (mDM) de acordo com KESKINTEPE et al. (1995). Posteriormente, foram inclinados em ângulo de $45^{\circ}$ com a finalidade de se obter a migração espermática ascendente. Decorridos 45 minutos do "swim up", $0,8 \mathrm{~m} \ell$ da parte superior de cada tubo foi aspirada e centrifugada a $350 \mathrm{~g}$ por 10 minutos. Descartado o sobrenadante, $200 \mu \ell$ do meio $\mathrm{mDM}$ contendo $10 \mu \mathrm{g} / \mathrm{m} \ell$ de heparina foi acrescentado a $200 \mu \ell$ do pellet resultante da centrifugação.

Antes da exposição dos oócitos aos espermatozóides, 5 estruturas de cada repetição $(\mathrm{n}=150)$ foram retiradas para terem suas configurações cromossômicas avaliadas conforme a 
técnica de COSTA et al. (1997). As demais foram lavadas em $\mathrm{mDM}$ e transferidas para as gotas de $100 \mu \ell$ do mesmo meio sob óleo de parafina esterilizada, local onde era depositada a suspensão espermática na concentração final de 1 X $10^{6}$. Imediatamente após, os gametas foram incubados em condições idênticas às de maturação durante o período de 18 horas.

As células da granulosa, obtidas através da aspiração dos folículos com seringa de $5 \mathrm{~m} \ell$ e agulha $18 \mathrm{~g}$, foram cultivadas, por 48 horas, em gotas de $100 \mu \ell$ do meio KSOM de acordo com ROSENKRANS et al. (1993), suplementado com $10 \%$ de soro de vaca no estro.

Os presumíveis zigotos foram desnudados e transferidos para as gotas de $100 \mu \ell$ contendo o meio KSOM suplementado com $10 \%$ de soro de vaca em estro e monocamada de células da granulosa. Sob óleo de parafina, essas estruturas foram incubadas à $39^{\circ} \mathrm{C}$ em atmosfera úmida com $5 \%$ de $\mathrm{CO}_{2}$ durante sete dias.

A análise dos dados das configurações cromossômicas foi efetuada pelo teste QuiQuadrado considerando-se o nível de $1 \%$ de significância. Os achados de clivagem, degenerados e blastocisto foram transformados em $\sqrt{X+1}$ ( $X=$ número de embriões) para atender as exigências da análise de variância paramétrica, quando se aplicou o teste $\mathrm{F}$ em níveis de $5 \%$ e $1 \%$ de probabilidade, bem como o teste de comparação de médias pelo teste de Tukey ao nível de 5\% de probabilidade.

\section{RESULTADOS E DISCUSSÃO}

Os resultados da análise das configurações cromossômicas apontaram que a concentrações de $20 \mu \mathrm{g} / \mathrm{m} \ell$ e $40 \mu \mathrm{g} / \mathrm{m} \ell$ de FSH-p retardaram ou inibiram o processo de maturação dos oócitos (Tabela 1), haja vista ter proporcionado menores porcentagens $(\mathrm{P} \leq 0,01)$ de estruturas no

Tabela 1 - Porcentagem das configurações cromossômicas de oócitos bovinos submetidos a maturação in vitro em meio de cultura suplementado com diferentes concentrações de FSH-p.

\begin{tabular}{ccc}
\hline Tratamentos & $\begin{array}{c}\text { Oócitos avaliados } \\
\mathrm{n}\end{array}$ & $\begin{array}{c}\text { Metáfase II } \\
\%\end{array}$ \\
\hline $10 \mu \mathrm{g} / \mathrm{m} \ell$ & 50 & $81,8^{\mathrm{a}}$ \\
$20 \mu \mathrm{g} / \mathrm{m} \ell$ & 50 & $55,5^{\mathrm{b}}$ \\
$40 \mu \mathrm{g} / \mathrm{m} \ell$ & 50 & $50,0^{\mathrm{b}}$ \\
\hline
\end{tabular}

Letras diferentes na mesma coluna significa diferença estatística $(\mathrm{P} \leq 0,01)$. estádio de metáfase II, quando comparada com a concentração de $10 \mu \mathrm{g} / \mathrm{m} \ell$ dessa gonadodrofuna. O efeito deletério que esta gonadotropina pode exercer sobre a retomada da meiose de oócitos bovinos (GONÇALVES et al., 1996), motivou alguns pesquisadores não recomendarem sua incorporação ao meio de maturação (BRACKETT et al., 1989) ou a utilizarem em baixa concentração (FUKUSHIMA \& FUKUI, 1985; SAEKI et al., 1991; HARPER \& BRACKETT, 1993; MONTAGNER, 1999). Todavia, outros autores, como ZUELKE \& BRACETT (1990), admitiram que altos índices de maturação de oócitos bovinos podem ser obtidos utilizando-se amostras de FSH contaminado com LH. Com o respaldo dos resultados encontrados por esses autores, foi esperado que as concentrações de $20 \mu \mathrm{g} / \mathrm{m} \ell$ e $40 \mu \mathrm{g} / \mathrm{m} \ell$ desse FSH-p contaminado com $20 \%$ de LH determinassem índices mais expressivos de maturação em conseqüência da atuação conjunta dessas gonadotropinas proporcionarem condições ideais para a ação de mensageiros intracelulares.

As taxas de clivagem variaram de $62,0 \%$ a $65,0 \%$ e a não constatação de diferença $(P \geq 0,05)$ entre elas (Figura 1) não tem o respaldo dos resultados encontrados na análise citogenética ao ser verificado que, aproximadamente, metade dos oócitos submetidos a maturação com as concentrações de $20 \mu \mathrm{g} / \mathrm{m} \ell$ 40 $\mu \mathrm{g} / \mathrm{m} \ell$ de FSH-p não alcançaram o estádio de metáfase II. Apesar deste achado se mostrar, em princípio, de maneira paradoxal, é possível admitir que essas concentrações devem ter apenas retardado a maturação nuclear, pois se tivesse ocorrido inibição do processo de maturação nuclear, a taxa de clivagem seria estatisticamente diferente daquelas dos demais tratamentos. Taxas de clivagem variando de $37,6 \%$ a $86,7 \%$ foram obtidas por SIRARD $\boldsymbol{e t}$ al . (1988), YOUNIS et al. (1989), ZUELKE \& BRACKETT, (1990), HARPER \& BRACKETT,

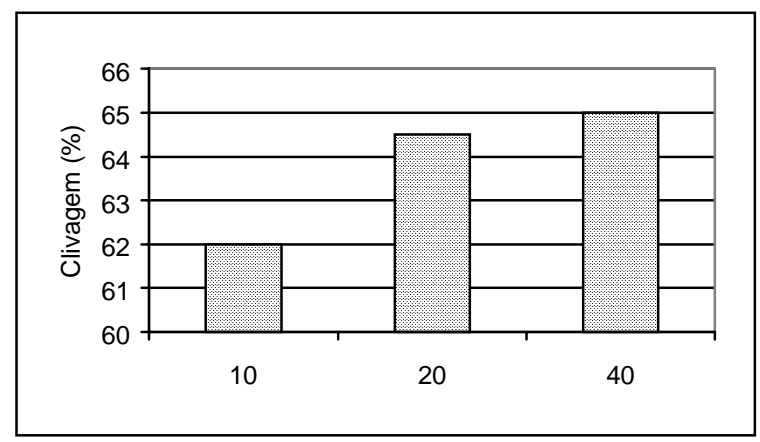

Figura 1 - Porcentagens de clivagem obtidas em diferentes concentrações $(\mu \mathrm{g} / \mathrm{m} \ell)$ de FSH-p comercial. Não foi observada diferença $(\mathrm{P} \geq 0,05)$ entre os tratamentos. 
(1993), ALVES et al. (1999), MONTAGNER, (1999) e OLIVEIRA et al. (1999ab). A diferença das porcentagens entre os autores e aquelas aqui obtidas pode ser atribuída aos diferentes protocolos adotados para a fecundação in vitro de oócitos bovinos, a condição corporal dos animais e ao fato de se ter utilizado animais Bos indicus provenientes de regiões que apresentavam longo período de estiagem, os quais aliados ao temperamento estressado dessa espécie, pode ter determinado alterações intracelulares, impossíveis de detectação ao simples exame morfológico do oócito.

No que diz respeito ao desenvolvimento embrionário, a partir das estruturas clivadas, não foi observada diferença $(\mathrm{P} \geq 0,05)$ entre os diferentes tratamentos (Figura 2). Porcentagens de 5\% a 39,5\% de blastocistos foram verificadas por SAEKI $\boldsymbol{e t}$ al. (1991), HARPER \& BRACKETT (1993), KIM et al. (1993), KESKINTEPE et al. (1995) e SIMPLÍCIO et al. (1997). Do total de oócitos inseminados foram obtidas porcentagens de blastocistos equivalentes a $11,0 \%(10 \mu \mathrm{g} / \mathrm{m} \ell), 12,5 \%$ $(20 \mu \mathrm{g} / \mathrm{m} \ell)$ e $10,5 \%(40 \mu \mathrm{g} / \mathrm{m} \ell)$ e das estruturas que clivaram, $17,6 \% \quad(10 \mu \mathrm{g} / \mathrm{m} \ell), 19,5 \% \quad(20 \mu \mathrm{g} / \mathrm{m} \ell)$ e $16,3 \%(40 \mu \mathrm{g} / \mathrm{m} \ell)$ evoluíram até estádios de blastocistos (Figura 2).

Era esperado um maior índice de blastocistos nos diversos tratamentos, embora haja grande variação nos resultados reportados na literatura. Uma das justificativas para os resultados obtidos pode ter sido o fato de que o meio KSOM não foi suplementado com aminoácidos essenciais e não essenciais, pois além de atuarem como substrato energético, reguladores de $\mathrm{pH}$ e como sintetizadores de proteínas, segundo ROSENKRANS \& FIRST (1994), atuam regulando a osmolaridade intracelular conforme reportado por VAN WINKLE $\boldsymbol{e t}$ al. (1990). Adicionando aminoácidos essenciais e não essenciais ao KSOM, MONTAGNER (1999), em

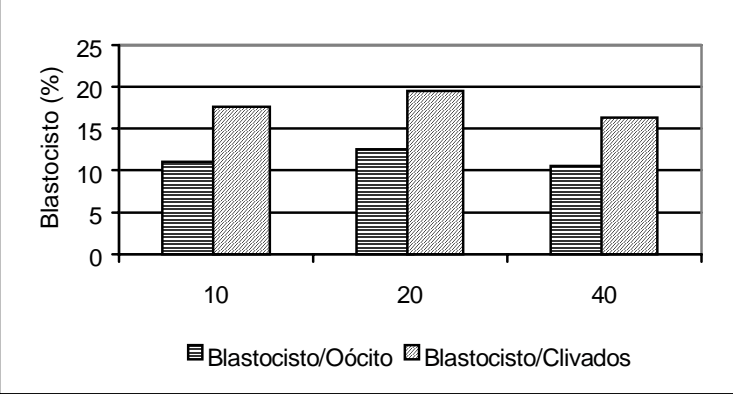

Figura 2 - Produção de blastocistos nas diferentes concentrações $\mu \mathrm{g} / \mathrm{m} \ell$ de FSH-p, calculadas em relação ao total de estruturas inseminadas e clivadas. Não foi observada diferenças $(P \geq 0,05)$ entre os tratamentos. um de seus experimentos, registrou porcentagens de blastocistos equivalentes, respectivamente, a $17,5 \%$ quando considerou a relação blastocisto/oócitos e $23,9 \%$ ao relacionar blastocisto/clivados. Outro aspecto que deve ser abordado é o fato de que durante as primeiras 72 horas de co-cultura existe a produção de amônia que é tóxica para o embrião (GARDNER, 1994). Como no protocolo aqui adotado não houve substituição de parte do meio de cultura, admite-se, com base nas argumentações de KESKINTEPE \& BRACKETT (1996) e de MARTINS JR et al. (1997), que este fato também pode ter exercido influência sobre os resultados.

\section{CONCLUSÕES}

Apesar das concentrações de $20 \mu \mathrm{g} / \mathrm{m} \ell$ e $40 \mu \mathrm{g} / \mathrm{m} \ell$ de FSH-p interferirem na maturação nuclear, não exercem influência sobre a clivagem. Além disso, embriões provenientes de oócitos submetidos ao processo de maturação com qualquer das concentrações de FSH-p testadas desenvolvemse normalmente até os diferentes estádios de blastocisto.

\section{AGRADECIMENTO}

Ao Técnico de Laboratório Alcir Loureiro de Carvalho Filho pelo apoio na condução deste trabalho.

\section{FONTES DE AQUISIÇÃO}

${ }^{a}$ Medium 199/25 mM HEPES modification - Sigma

${ }^{\mathrm{b}}$ Pluset - Serono Veterinária

\section{REFERÊNCIAS BIBLIOGRÁFICAS}

ALVES, J.D.R., OLIVEIRA, M.A.L., LIMA, P.F., et al. An In vitro maturation of Bos indicus oocytes with different concentrations of FSH, Recife, PE, 1999. In: CONGRESSO PERNAMBUCANO DE MEDICINA VETERINÁRIA, 1999.,Recife, PE. Anais... Recife : Sociedade Pernambucana de Medicina Veterinária, 1999. p.311-312.

BRACKETT, B.G., YOUNIS, A.I., FAYRER-HOSKEN, R.A Enhanced viability after in vitro fertilization of bovine oocytes matured in vitro with high concentrations of luteinizing hormone. Fertil Steril, v.52, n.2, p.319-324, 1989

COSTA, E.P., VALE FILHO, V.R., NOGUEIRA, J.C., $\boldsymbol{e} \boldsymbol{t}$ al Técnica para avaliação do estágio de maturação nuclear de oócitos bovinos cultivados in vitro. Arq Bras Med Vet Zoot, v.49, n.4, p.433-440, 1997.

FUKUI, Y. Effect of sera and the steroid hormones on development of bovine oocytes matured and fertilized in vitro and co-cultured with bovine oviduct epithelial cells. J Anim Sci, v.23, p.1318-1323, 1989. 
FUKUSHIMA, M., FUKUI, Y. Effect of gonadotropins and steroids on the subsequent fertilizability of extrafollicular bovine oocytes cultured in vitro. Anim Reprod Sci, v.9, p.323-332, 1985.

GARDNER, D.K. Mammalian embryo culture in the absence of serum or somatic cell suport. Cell Biol Int, v.18, p.11631179, 1994.

GONÇALVES, P.B.D., HÉRNANDEZ, A.G., SCHWEITZER, C.M., et al. Aspects of the oocyte maturation and in vitro fertilization in the bovine. Arq Fac Vet Zoot UFRGS, v. 24 p.98-116, 1996 (Supl)

HARPER, K.M., BRACKETT, B.C. Bovine blastocyst development after in vitro maturation in a defined medium with epidermal growth factor and low concentrations of gonadotropins. Biol Reprod, v.48, p.409-416, 1993.

KESKINTEPE, L., BRACKETT, B.G. In vitro developmental competence of in vitro matured bovine oocytes fertilized and cultured in completely defined media. Biol Reprod, v.55, p.333-339, 1996.

KESKINTEPE, L., BURNLEY, C.A., BRACKETT, B.G. Production of viable bovine blastocysts in defined in vitro conditions. Biol Reprod, v.52, p.1410-1417, 1995.

KIM, J.H., NIWA, K., LIM, J.M., et al. Effects of phosphate, energy substrates, and amino acids on development of in vitro matured in vitro fertilized bovine oocytes in a chemically defined, protein-free culture medium. Biol Reprod, v.48, p.1320-1325, 1993.

MARTINS JR, A., CAMPOS, M.M., BRACKETT, B.G. Improved bovine embryo production by reducing changes of culture medium in defined in vitro conditions. Rev Bras Reprod Anim, v.21, n.2, p.85-89, 1997

MONTAGNER, M.M. Produção in vitro de embriões bovinos com meios congelados, hepes e retinol. Santa Maria - RS, 1999. 68p. Dissertação (Mestrado em Medicina Veterinária) - Programa de Pós-graduação em Medicina Veterinária, Universidade Federal de Santa Maria, 1999.

OLIVEIRA, M.A.L., LIMA, P.F., ALVES, J.D.R., et al. Desenvolvimento de embriões bovinos fecundados in vitro, Recife, PR., 1999. In: CONGRESSO PERNAMBUCANO DE MEDICINA VETERINÁRIA, 4, 1999, Recife, PE. Anais... Recife : Sociedade Pernambucana de Medicina Veterinária, 1999a. p.295-296 363p.

OLIVEIRA, M.A.L., LIMA, P.F., ALVES, J.D.R., et al. Transporte de oócitos e manipulação de zigotos e embriões de bovinos em diferentes temperaturas. Ciênc Vet Tróp, v.2, n.1, p.45-49, 1999b.
RICHARDS, J.S. Maturation of ovarian follicles: actions and interactions of pituitary and ovarian hormones on folicular cell differentiation. Physiol Rev, v.60, n.1, p.51-89, 1980.

ROSENKRANS, C.F., FIRST, N.L. Effect of free amino acids and vitamins on cleavage and development rate of bovine zygotes in vitro. J Anim Sci, v.72, p.434-437, 1994.

ROSENKRANS, Jr. C.F., ZENG, G.Q., McNAMARA, G.T., et al. Development of bovine embryos in vitro as affected by energy substrates. Biol Reprod, v.49, p.459-462, 1993.

SAEKI, K., HOSHI, M., LEIBFRIED-RUTLEDGE, M.L., $\boldsymbol{e}$ t al. In vitro fertilization and development of bovine oocytes matured in serum-free medium. Biol Reprod, v.44, p.256260, 1991.

SCHNEIDER, M.R. Avaliacao de sistemas de armazenamento de oocitos e embrioes bovinos produzidos in vitro. Porto Alegre - RS, 1997. 104p. Disertação (Mestrado em Medicina Veterinária) - Programa de Pós-graduação em Ciências Veterinárias, Universidade Federal do Rio Grande do Sul, Faculdade de Veterinária, 1997.

SIRARD, M.A., PARRISH, J.J., WARE, C.B., et $\boldsymbol{a l}$. The culture of bovine oocytes to obtain developmentally competent embryos. Biol Reprod, v.39, p.546-552, 1988.

SIMPLÍCIO, A.A., BRACKETT, B.G., KESKINTEPE, L. Produção de embriões in vitro em meios quimicamente definidos. Arq Fac Vet UFRGS, v.25, n.1, p.302, 1997.

SUSS, U., WUTHRICH, K., STRANZINGER, G. Chromosome configurations and time sequence of the first meiotic division in bovine oocytes matured in vitro. Biol Reprod, v.38, p.871-880, 1988 .

VAN WINKLE, L.J., HAGHIGH, N, CAMPIONE, A.L. Glycine protects preimplantation mouse conceptuses from a detrimental effect on development of the inorganic ions in oviductal fluid. J Exp Zool, v.253, p.215-219, 1990.

YANG, X., KUBOTA, C., SUZUKI, H., et al. Control of oocyte maturation in cows - Biological factors. Theriogenology, v.49, p.471-482, 1998.

YOUNIS, A.I., BRACKETT, B.G., FAYRER-HOSKEN, R.A. Influence of serum and hormones on bovine oocyte maturation and fertilization in vitro. Gam Res, v.23, p.189201, 1989

ZUELKE K.A., BRACKETT, B.G.. Luteinizing hormoneenhanced in vitro maturation of bovine oocytes with and without protein suplementation. Biol Reprod, v.43, p.784787, 1990. 